\title{
Movimento curricular para prática docente de estudantes-professores em formação
}

\author{
Lucinalva Andrade Ataíde de Almeida \\ Janssen Felipe da Silva \\ Carla Patrícia Acioli Lins \\ Universidade Federal de Pernambuco
}

\section{Resumo}

Este artigo tem por objetivo analisar a contribuição do currículo vivido da formação inicial no curso de pedagogia para a prática docente dos alunos/ professores, e, a fim de discutir a temática, tomamos como lente teórica, entre outros, Ball (2006) e Bourdoncle (1991). Como procedimento de coleta de dados, utilizamos a entrevista semiestruturada, com base na Análise de Discurso (Orlandi, 2010), por considerar a análise dos enunciados do discurso como uma produção simbólica. Os resultados apontaram que o currículo vivido possibilita a aproximação das discussões teóricas com as demandas do campo de atuação estabelecendo o diálogo entre a teoria e a prática e o processo de profissionalização docente.

Palavras-chave: Currículo vivido. Formação de professores. Políticas curriculares. 


\section{Curricular movement for the practice of teaching of students-teachers in training}

This article aims to analyze the curriculum lived contribution of initial training in pedagogy course for teaching students / teachers and to discuss the issue, we take as a theoretical lens, among others, Ball (2006) and Bourdoncle (1991). And as data collection procedure semi-structured interviews, using Discourse Analysis (Orlandi, 2010), considering the analysis of the statements of the speech as a symbolic production. The results showed that the lived curriculum allows the approximation of the theoretical discussions with the demands of the field by establishing dialogue between theory and practice and the teacher professionalization process.

Keywords: Experienced program. Training. Curricular Policies

\section{Movimiento curricular para la práctica docente de estudiantes/profesores en formación}

Este artículo tiene como objetivo analizar el plan de estudios vivenciado en la formación inicial en el curso de pedagogía para la enseñanza de los estudiantes/ profesores. Para tratar del asunto, tomamos como una lente teórica, entre otros, Ball (2006) y Bourdoncle (1991); y entrevistas semiestructuradas como procedimiento de colecta de datos, utilizando el Análisis del Discurso (Orlandi, 2010), considerando el análisis de las declaraciones del discurso como producción simbólica. Los resultados mostraron que el currículo vivenciado permite la aproximación de las discusiones teóricas con las demandas del campo de actuación mediante el establecimiento del diálogo entre la teoría y la práctica y el proceso de profesionalización docente.

Palabras-clave: Currículo Vivenciado. Formación. Políticas Curriculares. 


\section{Introdução}

0 presente artigo toma como base a discussão em torno da formação de professores no ensino superior e é resultado do projeto de pesquisa intitulado "Políticas Curriculares para Formação de Professores: uma análise do currículo vivido pelas IES no Curso de Pedagogia". Nessa direção, buscamos analisar, a partir do currículo da formação inicial de professores no curso de pedagogia, a contribuição da formação para a prática docente dos alunos/professores de uma instituição de ensino superior (IES) pública do agreste pernambucano, localizada no município de Caruaru. Para tanto, mapearam-se os componentes curriculares que, na ótica dos alunos e professores, apresentavam maior possibilidade de diálogo com a realidade vivenciada em sala de aula no exercício profissional.

Para tanto, partirmos da contribuição teórica de currículo ancorada na abordagem do ciclo de políticas de Ball, que aponta a relação da produção das políticas educacionais em três principais contextos: o contexto de influência, em que as políticas são pensadas e discutidas na esfera legal; o contexto de produção de texto, em que os textos são prescritos; e, por fim, o contexto da prática, locus onde a política de currículo é materializada. (Ball apud Mainardes, 2006)

Ressaltamos que Ball tem sua centralidade discursiva no âmbito das políticas educacionais; por essa razão, utilizamos essa perspectiva teórica para analisar as políticas de currículo, visto estas configurarem-se como uma das dimensões da política educacional. Nesta linha, Busnardo e Lopes (2010, p. 99) apontam que “[...] a produção de políticas curriculares é resultado de intensos e múltiplos processos de (re)leituras, apropriações, reinterpretações e ressignificações que envolvem todos os contextos do ciclo de produção de políticas - influência, produção de textos e prática"1. Nesse sentido, entendemos que as políticas de currículo da formação de professores no ensino superior, curso de pedagogia, são produções resultantes da circularidade de diversos discursos em diferentes contextos $^{2}$, que se apresentam em constante movimento no cotidiano da formação e materializados na prática docente.

É importante destacar que tomamos o movimento curricular investigado como aquele que é vivenciado no contexto da prática. Nesse sentido, elucidamos que o currículo como contexto da prática se corporifica nas práticas docentes

1. Sobre as relações entre os contextos de produção de políticas, ver Ferreira (2012), que, ao tratar das reformas na educação superior, entre os períodos de 1995-2011, aponta uma diversidade de discursos e contextos, que hibridizam-se e distanciam-se, pautados por marcas sócio-históricas.

2. Almeida, Leite e Santiago (2013) discutem em torno das políticas curriculares para a formação de professores no Brasil e em Portugal, evidenciando que as reformulações curriculares nos contextos luso e brasileiro não ocorrem linearmente, tampouco se limitam a um enunciado estático. 
que perpassam as relações sociais no espaço escolar e/ou acadêmico, sendo materializado pelos alunos, professores das instituições, especialmente os professores e alunos no âmbito da sala de aula, evidenciando a historicidade e a intencionalidade do processo formativo (Souza Júnior, 2007). Assim, o contexto da prática está relacionado com o que se diz, com o que se pensa, com o que se pode dizer, onde se pode dizer e com que autoridade se pode fazer. (Ball, 2006)

Destacamos que a compreensão de formação que pauta este artigo parte do entendimento da inconclusão e incompletude tanto da teoria quanto da prática. Não há teoria que seja conclusiva e que se baste a si mesma, da mesma forma que não há prática que esteja acabada ou pronta. A indissociabilidade entre a teoria e a prática possibilita a atualização reflexiva de ambas e intensifica o processo de construir sentidos sobre a identidade profissional do professor e, consequentemente, sobre seu exercício profissional.

Dessa forma, a formação não se limita, nem se constitui, unicamente, pela dinâmica de acumulação de teorias e de práticas. A formação possui, como um de seus elementos fundantes, a reflexão crítica sobre ambas. Essa reflexão crítica se materializa na construção e (re)construção da teoria e da prática. É, então necessário que a formação se constitua em processos nos quais sejam estabelecidas, constantemente, relações entre o cotidiano das IES e das escolas.

0 movimento entre o cotidiano das IES e a escola é fundamental na perspectiva de formação que não se centra na transmissão de informações aos sujeitos para deixá-los com a cabeça cheia, mas aquela que possibilita construir o que Morin (2000) denomina de cabeça feita, isto é, reformar seu pensamento e reestruturar sua prática. Por isso, a formação não é acumulativa e sim reflexiva e propositiva, possuindo uma natureza transformadora e contextualizada. Será transformadora na medida em que é o tempo-espaço de transformação das ideias e das ações de quem está envolvido no processo de formação (professores e estudantes), mas essa transformação necessita de um contexto que, por sua vez, se constitui da integração entre campo de formação (IES) e campo de atuação (escola da educação básica).

A formação inicial, assim, permite o encontro sistemático entre os campos de formação e de atuação para fomentar diálogos teórico-práticos em torno dos problemas que se enfrentam e das soluções que se podem tecer na vivência simultânea da formação e da atuação profissional. Esta situação favorece o entrelaçar de ideias, de valores, de costumes e de experiências constituintes do cotidiano da escola e da sala de aula a serem refletidas no processo de formação. Este entrelace compõe redes de aprendizagem dos licenciandos ao fazer da reflexão fundamentada na prática pedagógica, individual e coletiva, o cerne do processo formativo. 
Compreender a formação, nessa linha de pensamento, exige partirmos da concepção do professor como Intelectual Reflexivo Transformador: profissional pensante e atuante que reflete sua prática pedagógica e docente, reelaborando-a e reelaborando-se, um profissional que está em permanente dinâmica de desconstrução e reconstrução de si mesmo, de seus saberes e fazeres mediante a reflexão fundamentada e transformadora de sua realidade. A formação do professor como um Intelectual Reflexivo Transformador requer que a própria formação subsidie esse sujeito na relação teoria e prática, para que este possa questionar a formação que vivencia, indagando o próprio movimento curricular que se dá entre IES e a escola, isso porque entendemos a reflexão como produtora de uma revisão dos percursos anteriores e possibilidade de novos referenciais e mudanças, além de visualizarmos a importância de uma prática de reflexão como veículo de construção da formação de professores, na perspectiva críticoemancipatória.

Nessa linha de raciocínio, o currículo da formação do professor constitui-se de movimentos que possibilitam diálogos entre: a teoria e a prática; o pensar e o fazer; o campo de formação e o campo de atuação. Por isso, o currículo configurase como contexto de produção de sentidos sobre aquilo que fundamenta a prática pedagógica e docente na dinâmica de sua materialização. Dessa forma, na vivência curricular da formação do professor tanto se ressignifica a teoria quanto a prática no espaço-tempo da formação (IES) e no espaço-tempo da atuação profissional (escolas da educação básica).

É neste sentido que é importante que o currículo dos cursos de formação de professores possa garantir uma sólida base teórica e uma diversidade de experiências no campo de atuação profissional ${ }^{3}$. A ideia de currículo em movimento nos leva a compreender que o campo da formação inicial não se restringe às IES. 0 ciclo do movimento curricular, da vivência curricular, se completa no diálogo reflexivo e transformador entre a sólida base teórica e as experiências do campo profissional. Esse diálogo reflexivo e transformador contribui para dar início à constituição da identidade profissional do professor e de sua prática pedagógica e docente.

Nessa discussão, faz-se necessário elucidar o entendimento sobre a prática pedagógica e a prática docente. De acordo com Souza (2006), a prática pedagógica pode ser compreendida como uma práxis que se caracteriza pela intencionalidade pela qual as ações são dirigidas de maneira coletiva e institucionalizada. Além

3. França e Almeida (2013) apontam uma discussão a esse respeito quando problematizam as políticas curriculares sob o viés das novas demandas na formação do pedagogo, principalmente no que se refere à atuação docente em espaços não escolares. 
disso, a prática pedagógica se constitui pela relação e dinamicidade de outras práticas que a compõem, a saber: a prática gestora, a prática docente, a prática discente e a prática epistemológica. Assim, entende-se que a prática docente ${ }^{4}$, que é desenvolvida pelo professor, é uma das dimensões da prática pedagógica.

A partir da compreensão de que é importante estudar o currículo como prática no curso de pedagogia, que contribui não só com a formação, mas também com o processo de profissionalização docente, é que buscamos apoio nos estudos sobre profissões, especificamente sobre a profissão docente. Destacamos que tais estudos são bem diversos e não consensuais do ponto de vista teórico; assim, adotamos os estudos desenvolvidos por Bourdoncle (1991) sobre o conceito de profissionalização. 0 modelo proposto pelo autor, a nosso ver, permite a verificação da profissionalização na dimensão dos conhecimentos e das práticas do grupo e do desenvolvimento e incorporação de valores, normas, regras que são próprios da profissão e que são adquiridos, em parte, já na formação inicial. Daí a importância de articulação entre a formação inicial - as experiências e vivências curriculares - e o debate sobre profissionalização, uma vez que este processo é introduzido no momento da formação inicial do professor. Salientamos, a fim esclarecer a articulação entre currículo, formação e profissionalização, que, na discussão que Bourdoncle (1991) realiza sobre profissões, há três estados decorrentes do processo de profissionalização: profissionalidade, profissionismo e profissionalismo.

Como profissionalidade, o autor define a natureza elevada e racional dos saberes e a competência para utilizá-los no exercício profissional. Essas capacidades são desenvolvidas mediante a ação dos especialistas e a formação contínua, promovendo o aperfeiçoamento das competências e a utilização de saberes racionais no exercício da profissão, possibilitando maior eficácia coletiva e individual. Esse processo de aprimoramento é também denominado desenvolvimento profissional e, em nossa perspectiva, também se inicia na formação inicial em interdependência com o currículo que denominamos de vivido ${ }^{5}$.

Osegundo estado denominado de profissionismo não se apoia nos conhecimentos e nas capacidades exigidas pela prática, mas faz referência às estratégias e aos discursos utilizados pelo grupo profissional para reivindicar o reconhecimento

4. Para um maior aprofundamento em torno da prática docente, desenvolvida pelo professor, que é uma das dimensões da prática pedagógica criativa, reflexiva e produtora de conhecimentos, e, portanto, palco de sistematizações teóricas ancoradas na prática e do fazer articulado à reflexão, ver Melo e Almeida (2014).

5. A título de aprofundamento dos sentidos acerca da profissionalidade, ver Carmo (2013), que disserta sobre discursos em torno da profissionalidade das estudantes/professoras em formação a partir do componente curricular pesquisa e prática pedagógica do curso de pedagogia. 
de suas atividades. Nesse caso, profissionalização, segundo Bourdoncle (1991), designa o processo de aperfeiçoamento coletivo do status social da atividade, como exemplo, a ação dos sindicatos e das associações.

o último estado apontado por Bourdoncle (1991) para descrever profissionalização faz referência à adesão ao discurso e às normas, à consciência profissional, à exigência de eficiência que são estabelecidas coletivamente considerando os sentidos precedentes. 0 processo que conduz a esse estado é a socialização profissional, esse sentido é chamado pelo autor de profissionalismo.

Diante da discussão que realizamos e tendo em vista o objetivo deste artigo, apresentaremos a seguir o caminho metodológico da pesquisa, assim como discutiremos os principais resultados do estudo e teceremos algumas considerações finais.

\section{Traçando um caminho metodológico}

A escolha do caminho para buscar respostas às indagações sobre quais as contribuições do currículo vivido no curso de pedagogia para a prática docente do aluno/professor em formação, em uma IES pública no município de Caruaru, caracteriza-se por um processo de opção teórico-metodológica que se dá já no momento de sua gênese, ao se escolher o objeto de estudo. A partir de então, traçamos o caminho metodológico que melhor pudesse responder às indagações acerca do objeto de pesquisa e dos instrumentos indispensáveis na busca e análise dos dados da investigação.

Neste sentido, acreditamos que a temática de estudo não poderia ser entendida, na sua amplitude, por meio de métodos restritos à execução de variáveis; em vista disso buscamos fazer uso de uma análise qualitativa da realidade investigada, o que significa, segundo Minayo (2008), compreender os sentidos e significados dos elementos singulares presentes nos fenômenos sociais e humanos como o são as políticas curriculares corporificadas nos cursos de formação de professores e inseridas numa realidade heterogênea.

Para a escolha dos sujeitos da pesquisa nos utilizamos de questionários que foram distribuídos com os alunos do curso de pedagogia, para podermos traçar o perfil profissional dos estudantes do referido curso da IES investigada. Foram coletados os dados de um total de 136 alunos. De posse dos dados, sistematizamos um quadro-síntese no qual os sujeitos foram separados por atuação na docência por nível de ensino, tempo de docência, rede de ensino, demarcando também aqueles que nunca atuaram na área. Utilizou-se o termo extradocência para designar as outras funções que não correspondem ao magistério. 
Por meio desse mapeamento, identificamos que, dos $32 \%$ dos estudantes que continuavam atuando na docência, $37 \%$ lecionam na rede regular de ensino público, $50 \%$ na rede privada e $13 \%$ em programas governamentais. A partir desses dados, selecionamos os sujeitos que atuavam na rede pública de ensino. Assim, identificamos um total de 17 alunos, e, desses 17, selecionamos os alunos/professores que atuavam como docentes há mais de cinco anos. Dentre estes 4 alunos/professores apresentavam este tempo de atuação profissional. Ressaltamos que, para nos referirmos aos sujeitos participantes da pesquisa, utilizamos a nomenclatura de letras; assim os alunos-professores serão identificados no decorrer da análise como Sujeito "A", Sujeito "B", Sujeito "C" e Sujeito "D".

Como instrumento de coleta de dados, para a realização da análise, nos utilizamos da entrevista semiestruturada. A escolha desse procedimento toma como base a contribuição de Oliveira (2007), que aponta que a entrevista permite uma interação entre pesquisador e o sujeito estudado na possibilidade de aquisição de detalhes minuciosos sobre o que está sendo pesquisado. Assim, a produção discursiva resultante da entrevista constituiu e configurouse como o corpus de análise do discurso.

Destacamos que, em se tratando das políticas curriculares, estas se constituem de diversos discursos, tanto em formato de textos quanto em práticas; esta última configurou-se por meio dos discursos presentes nas falas dos sujeitos da pesquisa. Assim, a Análise do Discurso é a perspectiva teóricometodológica que norteou esta análise, pois, de acordo com Orlandi (2010), a Análise do Discurso é um instrumento mediador que procura compreender a língua na dimensão simbólica, como aspecto construtivo do ser humano e da sua história, que tem como objeto o discurso.

Utilizamo-nos da definição da Análise do Discurso - AD, proposta por Orlandi (2010), que aponta articulação entre linguagem, pensamento e mundo, que consiste em ultrapassar o dito no texto, buscando o não dito nos discursos, tendo em vista que a linguagem não se apresenta de forma transparente, daí a necessidade de encontrarmos o silenciado no discurso.

A opção metodológica constituiu-se de alguns elementos que não se limitaram à escolha de uma forma, mas a uma concepção com a qual nos identificamos e que responde melhor ao nosso problema de pesquisa. Apoiandonos na abordagem que se desvencilha da perspectiva teórica do paradigma clássico da linguística, pela qual as palavras têm valor em si mesmas e, por isso, o sentido consiste no que está ali, pronto e acabado, tomamos como linha teórica a $A D$, que traz como instrumento mediador, indispensável, a relação entre o homem e a realidade social, em que o discurso é seu objeto. 
No caso, o elemento fundante da $A D$ reside na construção de sentidos, os quais estão inseridos numa dimensão histórica. Logo, conforme Orlandi (2010), a linguagem não é transparente; por isso, cabe ao pesquisador, no processo, desconstruir o discurso, utilizando o método da AD. Essa metodologia estrutura-se a partir do dizer com que nos deparamos; da delimitação do nosso corpus a ser analisado; do interdiscurso; da memória discursiva; do jádito anteriormente e, finalmente, do não dito, que constitui o silêncio.

Assim, a AD, como instrumental metodológico, apresenta-se como possibilidade de entendermos o processo de constituição do discurso que compõe o discurso presente na fala dos sujeitos estudados no processo de materialização das políticas curriculares, mediante a análise da contribuição do currículo vivido da formação inicial no curso de pedagogia para a prática docente que está ancorada um projeto de formação e de sociedade.

A base da análise do discurso tem como pressuposto que o discurso não é fechado, pronto, acabado em si mesmo, mas tem articulação com outros discursos que, no caso deste estudo, referem-se à contribuição do currículo vivido da formação inicial no curso de pedagogia para a prática docente dos alunos/professores. Então, o discurso, em relação às políticas curriculares de formação de professores, no atual cenário brasileiro, ultrapassa a linguagem verbal e abstrata de um determinado grupo de linguistas. Na verdade, ele está inserido na realidade político-educacional brasileira. Por isso, a relevância de um desvencilhar-se do aspecto puramente verbal do discurso para que, assim, seja possível a análise dos sentidos que advêm deste discurso.

Tomando como base que o discurso define-se como sendo uma das “instâncias materiais (concretas) da intrínseca relação entre linguagem, pensamento e mundo", (Orlandi 2010, pp.17-18), valorizamos a historicidade do discurso em torno das políticas curriculares de formação docente no curso de pedagogia e a contribuição do currículo vivido da formação inicial no curso de pedagogia para a prática docente dos alunos/professores, procurando ver não apenas o que está escrito, mas o que está referendado em uma memória e o que, de alguma forma, foi falado anteriormente, aproximando-nos do que Orlandi denomina de interdiscurso.

A opção pela $A D$ se deu porque, na nossa pesquisa, buscamos extrair os sentidos dos textos, respondendo à questão "o que esse texto quer dizer?" e porque "a Análise de Discurso considera que a linguagem não é transparente. Desse modo ela não procura atravessar o texto para encontrar um sentido do outro lado. A questão é: como esse texto significa..." Orlandi (2010, pp. 17-18)

Os enunciados na AD são organizados e elencados de forma concreta, interligados a um contexto que não se constitui de forma abstrata, mas tal 
qual nos apresenta. Por isso, os discursos dos alunos/professores do curso de pedagogia estão ancorados na ordem do discurso das politicas curriculares e no discurso do currículo vivido e apresentam significados específicos em relação à contribuição do currículo vivido na formação de professores no curso de pedagogia.

Ressaltamos que tomamos enunciado como sendo a unidade mínima da análise, ou seja, diz respeito à fala acerca de um objeto dito por um sujeito que, nessa pesquisa, é aluno/professor do curso de pedagogia. E, assim, identificamos as formações discursivas que consistem no resultado das relações entre enunciados, que, como nos aponta Orlandi (2010), consistem em regionalizações do interdiscurso.

Assim, na produção discursiva das políticas curriculares, nos documentos, contempla-se a questão da relação teoria-prática como eixo para a produção e socialização do conhecimento, na formação do professor.

Portanto, o discurso presente na fala dos sujeitos estudados no processo de materialização das políticas curriculares torna-se o nosso objeto de investigação, o que demanda uma análise que se ocupa desses discursos.

\section{0 movimento dos componentes curriculares no processo de profissionalização docente}

Entendemos que o currículo vivido é a corporificação do currículo pensado e proposto e que, por isso, sua natureza é ainda mais dinâmica e os significados atribuídos às políticas curriculares são ainda mais circulares e não fixos. Isso significa dizer que pensar o currículo implica considerar os aspectos culturais e sociais. Essa realidade requer do professor o enfrentamento de alguns desafios, a exemplo da vivência de um currículo em movimento, portanto, de um processo de formação no ensino em movimento.

O conjunto dos enunciados apresentados pelos alunos/professores da IES nas entrevistas apontou quais os componentes curriculares que, na visão desses sujeitos, mais contribuíam para sua prática docente, ou seja, para sua profissionalidade. Ressaltamos que a organização do quadro 1 possibilita visualizar estes componentes. Organizamos os componentes por eixos que denominamos: pesquisa e prática pedagógica; metodologias; fundamentos da educação e gestão. 


\section{COMPONENTES CURRICULARES}

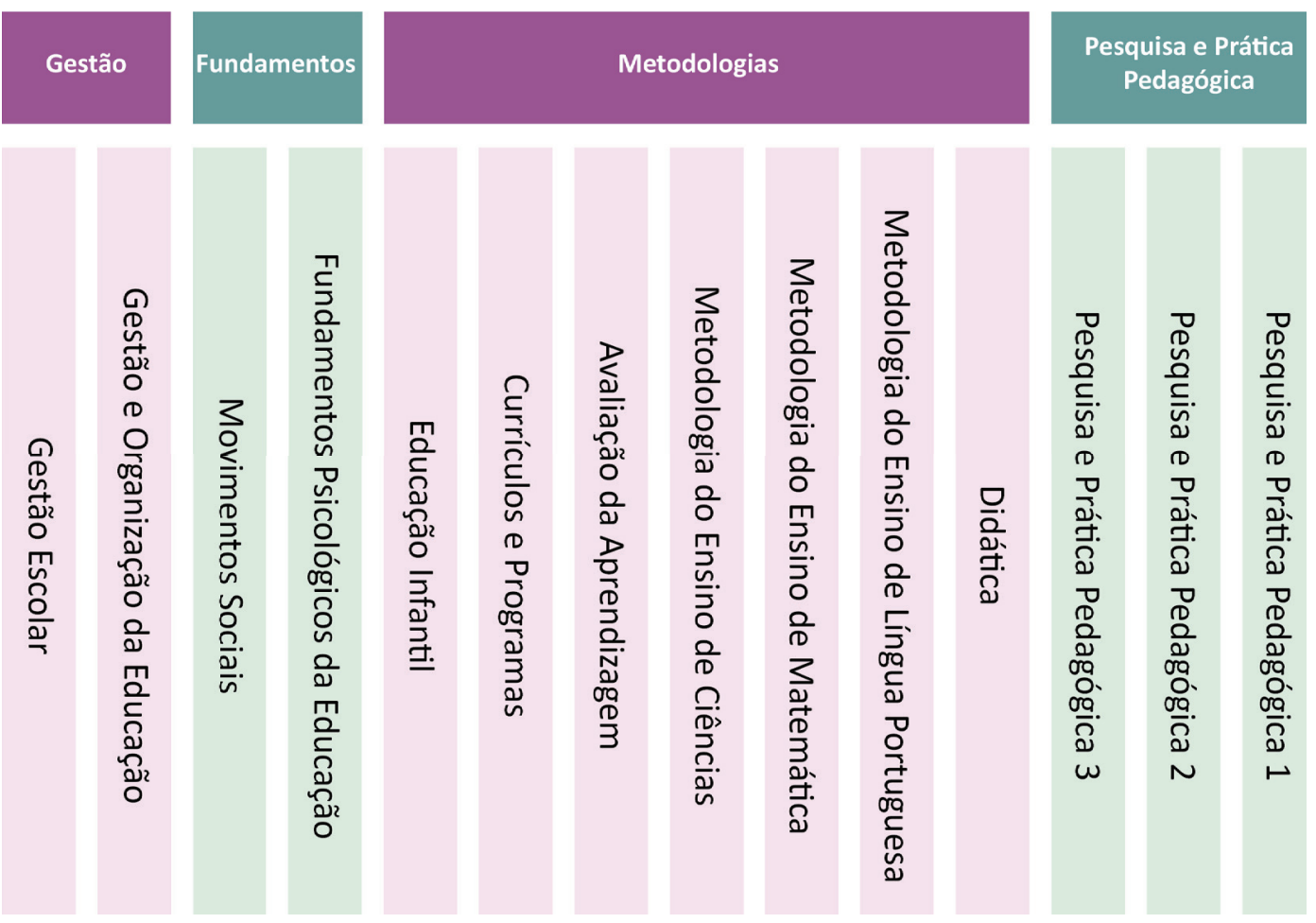

Fonte: Relatório Técnico Final, CNPq, 2012.

Como podemos visualizar no quadro acima, os alunos/professores destacaram, em seus enunciados, todos esses componentes como sendo os que efetivamente contribuem para sua prática docente. Todavia, para elucidar como acontece a contribuição, os alunos-professores apontaram apenas alguns desses componentes ${ }^{6}$.

Na análise tomamos como base aqueles componentes curriculares que foram recorrentes e enfatizados nas produções discursivas dos sujeitos, os quais que se revelaram como sendo os mais significativos no currículo vivido do curso de

6. Melo; Silva e Almeida (2014) trazem a construção histórica dos sentidos acerca da didática e do estágio supervisionado nos cursos de pedagogia como componentes que têm reafirmado seu lugar e papel na formação profissional docente, enquanto espaços de promoção da práxis reflexiva. 
pedagogia e que se configuraram como sendo o componente curricular que mais se aproximou na contribuição dada ao desenvolvimento de sua profissionalidade.

Assim, identificamos que os componentes citados, em sua maioria, constituem o eixo das metodologias, que são os componentes de natureza teórica que embasam a prática docente por meio de uma perspectiva teórica.

Os dados revelam que o componente de maior recorrência foi "metodologia do ensino de língua portuguesa" destacado no discurso de três alunos/professores como sendo um dos que mais contribuíram para o fazer docente. No entanto, os enunciados, apesar de não se mostrarem divergentes, apresentam especificidades próprias, como nos relatos dos sujeitos "A" e " $D$ " ao justificarem a importância do componente curricular para a prática docente na sala de aula:

0 ato de planejar, porque [o professor] ele, quando a gente planejava, ele dava assistência e ele é bem criterioso, que ele nos faz pensar nos detalhamentos do planejamento, porque fazer aquilo e não pensar no porquê da gente, mas pensar como se fosse o aluno pensando, que foi uma coisa que ele citou, e também na prática do meu conhecimento na, na aplicação do projeto de intervenção, conhecer os níveis silábicos dos alunos, eu achei muito interessante e que de fato é uma coisa que eu comecei a observar nos meus alunos, que eu não tinha esse conhecimento, e como eu trabalhava na época com alunos que se encontravam nessas fases aí pra mim foi mais fácil, pude conciliar teoria e a prática. (Sujeito A)

Você vai trabalhar, você vai ver como trabalhar a produção de texto, porque a gente trabalha na sala de aula como a gente aprende, como a gente estuda de $1^{\mathrm{a}}$ a $4^{\mathrm{a}}$ série por exemplo, reproduz né; ai, quando você trabalha, eu trabalhei metodologia 1, estou terminando de pagar a 2, ai na 1 você trabalha mais a questão de jogos, a importância de trabalhar com jogos na sala de aula, como desenvolve o cognitivo da criança, e na 2 você vai ver o que, por exemplo, a produção de texto, uma coisa que eu não sabia, eu trabalhava de uma forma mais solta, mas não sabia que existia uma fundamentação teórica, por exemplo, seria a importância da oralidade, de trabalhar, desenvolver a oralidade do aluno, a criticidade, a argumentação, entendesse? (Sujeito D)

Esses enunciados mostram que ambos os alunos/professores argumentam e exemplificam a relevância deste componente na relação com a sua profissionalidade docente, o que significa dizer que a formação vai se constituindo por meio da associação entre o conhecimento teórico e o conhecimento prático, em que ambos não podem restringir-se à dimensão técnica do exercício do trabalho, nem unicamente às expectativas individuais. Neste sentido, conforme Correia e Felgueira 
(1999), a formação é um espaço e um tempo de reinterpretação, que a atravessam tanto no âmbito inicial quanto no âmbito da formação continuada.

Assim, a organização curricular e o seu desenvolvimento são fatores que precisam ser repensados, uma vez que pensar o currículo significa rever o que necessita ser reconfigurado, o que é prescrito, pois o currículo precisa incorporar processos que o façam significativo.

Nesta direção, o sujeito "A" traz o elemento da vivência da relação teoria e prática a partir da aprendizagem dos níveis silábicos na fase da alfabetização dos alunos como sendo a contribuição do componente, enquanto o sujeito "D" indica a importância do respaldo teórico no trabalho docente. Neste sentido, ressaltamos que os discursos materializados nas falas dos sujeitos se aproximam, são reconhecidos e discutidos a partir de suas particularidades teóricas.

0 discurso do sujeito "A" revela o imbricamento entre a unidade teoria e prática no movimento da formação docente, desvelando as concepções tradicionais que dicotomizam a teoria e a prática, que, segundo Tardif (2000), oportunizaram a histórica crença de que

(...) o saber está somente do lado da teoria, enquanto a prática ou é desprovida de saber ou portadora de um falso saber (...) assim, o saber é produzido fora da prática (por exemplo, pela ciência, pela pesquisa pura, etc.) e sua relação com a prática, por conseguinte, só pode ser uma relação de aplicação. (Tardif, 2000, p. 119, grifo nossol

Neste sentido, a relação da teoria e da prática não é de oposição, mas uma relação dialética de elaboração e constituição de saberes, na medida em que se atua sobre a prática, embasando-se pela teoria, e que se produz teorização sobre o que é vivido no contexto da prática. Desse modo, o aluno-professor, ao relacionar as concepções sobre o ensino, estudadas e discutidas no âmbito da formação, no ensino superior, com a sua realidade no campo de atuação, destaca que, no que se refere à formação docente, há a possibilidade de superação de algum modo das perspectivas tradicionais de formação, além de apresentar que relação teoria e prática possibilita que os alunos passem a refletir sobre o que é prática, como se constitui sua prática e como vivenciar um processo de repensar a prática, no processo de profissionalização docente.

Ressaltamos que um dos aspectos de análise emergente no discurso do sujeito "A" é o planejamento escolar, que pode ser visto, como trabalha Vasconcellos (1995), como uma antecipação de uma ação a ser realizada, que não pode prescindir de fins, que se dá a partir e no âmbito de um tempo e espaço e com o uso de recursos materiais. Então, o ato de planejar é elemento que pode viabilizar 
ao professor voltar-se a seus objetivos direcionando-os à sua ação docente. Desse modo, o planejamento é uma atividade que está imbricada na prática do professor.

Analisando o discurso do aluno/professor " $D$ ", podemos identificar que o respaldo teórico apresenta-se como sendo de suma importância à contribuição do componente. Isto fica evidenciado na medida em que o aluno/professor exprime a relevância do embasamento teórico para ser o elemento condutor de sua prática docente, haja vista que é dessa fundamentação que o professor institui algumas práticas, significando o fazer de sua profissionalidade docente, o que, no dizer de Tardif (2008, p. 150), elucida que "uma teoria da atividade educativa nada mais é do que um modelo de ação formalizado, um conjunto sistemático e coerente de representações que nos esforçamos por justificar através das normas do pensamento racional ou científico", acentuando que essas teorizações oferecem aos professores a explicação para fazer o que fazem do modo como realizam ou para direcionar o seu fazer docente e assim efetivar suas ações.

Assim, quando o aluno/professor reconhece o lugar e o papel da fundamentação teórica e consegue a sua incorporação, materializada em sua prática, é possível estruturá-la de maneira a legitimar o seu fazer docente, a sua profissionalidade.

Faz parte da produção discursiva do aluno/professor a relevância do componente curricular "metodologia do ensino da matemática", que, segundo o sujeito "D", tem como contribuição reorientar a sua maneira de trabalhar a matemática na sala de aula:

Você vai ver uma maneira diferente de trabalhar com o aluno, que matemática tem que ter um objetivo, uma finalidade cotidiana, que você muitas vezes não pará [para] fazer essa análise, joga o conteúdo pelo conteúdo, e [pausa] pensando no feed back do aluno, entendesse? Tipo se ele aprendeu, se ele decorou uma fórmula de como se resolvesse isso estava bom, mas hoje você começa a olhar por outros olhos quando você trabalha com didática;, não é por ai não, ele precisa realmente compreender na situação do cotidiano, onde foi que ele empregou isso, onde é que ele vai empregar. (Sujeito "D")

0 discurso do aluno/professor " $D$ " mostra-nos que esse componente tem a mesma contribuição destacada naquele citado anteriormente (metodologia do ensino da língua portuguesal. A reelaboração do seu processo de profissionalidade docente dá-se por meio do aprofundamento e base teórica. Assim, pode-se considerar que os sujeitos destacam esses componentes não por serem de natureza prática, no sentido utilitário, mas por serem de natureza teórica, levando à possibilidade da prática reflexiva sobre o seu processo de profissionalidade docente e à vivência da práxis como atividade intencional que se concretiza a partir 
da relação teoria e prática.

Os alunos/professores também destacaram o componente curricular “avaliação da aprendizagem" como sendo um dos que mais contribuem para repensar a sua prática docente e, consequentemente, modificar a sua prática de ensino, tal como aborda o sujeito "B":

Porque a de avaliação foi, assim eu descobri muitos erros que cometi. (...) Ela ajudou assim ter mais facilidade com a realidade, porque discute assim coisas que a gente vive né, no cotidiano, e assim é mais como correção mesmo né, assim correção da nossa prática (...) os tipos de instrumentos que antes eu nem me preocupava com a forma do instrumento, como era avaliado, acho que eu avaliava de forma errada, assim, eu considero hoje que avaliava de maneira errada. (Sujeito "B")

0 discurso dessa aluna-professora sinaliza que esse componente é importante porque traz a relação com o cotidiano escolar vivenciado pelos professores no âmbito da escola. De acordo com Santiago (1997), o cotidiano da escola se caracteriza pelas manifestações, ações, gestos e relações sociais que materializam a escola, transformando-a em um organismo vivo. Neste aspecto, os alunos/ professores em seus discursos vão tecendo que a contribuição do componente se faz de maneira mais efetiva no momento em que se estabelece o diálogo com as questões presentes no âmbito da escola, com o que é vivenciado no cotidiano escolar.

Além disso, outro elemento destacado como contribuição do currículo vivido, tomando o componente da "avaliação da aprendizagem", é a possibilidade de refletir sobre a prática a partir do estudo teórico desenvolvido e discutido no curso de pedagogia. Vale salientar que outro componente que se destaca nesta mesma contribuição é denominado de "currículos e programas", que foi sublinhado pelo sujeito "C", que justifica que foi importante:

Para você se avaliar também, para você perceber coisas que você fazia e nem notava, eu realmente achei muito bom, para mim que sou profissional já atuante na área. (...) Para você perceber o que você faz em sala de aula, para você não tá com coisas tão bobas como essas, de levar um presentinho pra menina rosa, e para o menino azul, essas coisas simples que você acha que tá agradando, mas que por traz tem toda uma cultura, tem todo um currículo, né, oculto igual [o professor] fala, e que você ajuda a perdurar isso, ai serve pra isso. (Sujeito "C")

Percebemos que, mesmo sendo componentes diferentes, eles se aproximam primeiro por estarem no eixo curricular das metodologias, segundo por ambos 
contribuírem para os alunos-professores repensarem sua profissionalidade docente. Nessa perspectiva, os componentes possibilitaram aos sujeitos se voltar para seu fazer docente, sua profissionalidade e refletir sobre o seu cotidiano profissional, gerando inclusive uma mudança de postura. Segundo Zeichner (1993, p. 17), o conceito de professor como prático-reflexivo defende a ideia de que "o processo de compreensão e melhoria do seu ensino deve começar pela reflexão sobre sua própria experiência" e que os cursos de formação de professores possibilitem aos estudantes interiorizarem a capacidade de refletir e repensar a sua prática docente a fim de melhorar o ensino e seu desenvolvimento profissional.

Portanto, por meio da análise do discurso dos alunos/professores, foi possível identificar a contribuição do currículo vivido no processo de sua formação e da profissionalidade dos professores bem como que o currículo para formação de professores, no curso de pedagogia, apresenta-se como veículo essencial para sua profissionalização, uma vez que é o momento de introdução do aluno no campo profissional por meio de uma formação sólida, mediante a análise da realidade e a imbricação entre realidade, contexto científico e cultural.

Nesta linha, o currículo representa um campo de cultura, resistência, que vem trazendo consigo uma concepção de homem, mulher, sociedade e educação (Santiago, 1990, p. 25) 7 $^{0} 0$ debate em torno das políticas curriculares de formação distingue-se pelo processo de discussão e pelo conteúdo formador.

Salientamos que, embora os sujeitos enfatizem estes componentes, os alunosprofessores não deixam de reconhecer que todos que foram e estão sendo vivenciados na formação acadêmica de alguma forma são importantes para exercer a docência no seu campo de atuação, como podemos identificar nas falas dos sujeitos " $D$ " e "C" respectivamente: "Assim de alguma maneira as disciplinas que eu paguei até agora, todas elas contribuem"; "Eu acho que cada uma tem uma parte de contribuição".

Em síntese, podemos afirmar que a maior parte dos componentes curriculares destacados compõe o eixo das metodologias e, ao analisarmos os enunciados, fica claro que os sujeitos apontam esses componentes por serem de natureza teórica e possibilitarem o embasamento teórico para direcionar o processo de profissionalidade docente. Além disso, identificamos que, apesar de estarem presentes no discurso dos alunos/professores, os elementos de contribuição específica das áreas de cada componente curricular apontam para a relação da teoria e prática que é vivenciada pelas estudantes no curso e no campo de atuação, do mesmo modo que estes componentes são significativos por promoverem

7. Santiago (1990) faz uma análise do conceito de currículo, mostrando que este consiste numa corporificação dos interesses sociais e como luta que se processa na sociedade. 
a reflexão da sua prática docente quando entram em diálogo com o cotidiano escolar das estudantes ${ }^{8}$. Nessa direção, os discursos revelam que há indícios de uma formação acadêmica que não está distante da realidade do campo de atuação das alunas-professoras, possibilitando de algum modo o diálogo entre o que é vivido na graduação e na escola, entre os vários contextos.

\section{Considerações finais}

Foi possível perceber que as políticas curriculares são mais do que 0 documento curricular, ainda que o tomem como fonte principal para o seu pensar e elaborar. Os seus sentidos são construídos em espaços de formação, que no interior das Instituições de Ensino Superior se dão por meio de debates, embates e contestações.

Neste sentido, podemos entender que o currículo, mais especificamente, no caso de nossa pesquisa, a contribuição do currículo vivido da formação inicial no curso de pedagogia para a prática docente dos alunos/professores, não pode ser visto longe de suas dimensões teóricas e práticas, uma vez que ele incorpora além daquilo que foi pensado na elaboração das políticas curriculares, as interferências dos sujeitos protagonistas do processo de ensino/aprendizagem.

Assim, percebemos que o currículo, pensado no âmbito dos componentes curriculares recorrentemente nos enunciados pelos alunos/professores, são os componentes do eixo das metodologias do curso de pedagogia para a formação dos professores. Também constatamos que o currículo vivido nesses componentes curriculares não foi necessariamente materializado na prática docente do aluno/ professor tal qual foi pensado. E não o foi uma vez que o currículo vivido poderá ser interpretado, ressignificado e contextualizado, mediante as necessidades suscitadas em cada realidade escolar.

Então, podemos compreender que os currículos, longe de serem apenas pensados, são também praticados e, como afirma Oliveira (2012, p. 11), “são cotidianamente criados, a partir de redes de saberes/fazeres/valores(e sentidos) dos praticantes da vida cotidiana". Tal autora nos aponta, ainda, que justamente é preciso investigar não apenas as propostas oficiais, [...] "mas também as dinâmicas, complexas e mutantes redes no seio das quais os currículos são

8. Ao discutir os sentidos partilhados sobre estágio supervisionado e as contribuições para a prática docente do professor com experiência, Melo (2014) sinaliza as contribuições do diálogo da formação inicial com o cotidiano escolar, fundamentado na práxis, para o aprendizado profissional docente. 
criados e praticados".

Assim, a pesquisa realizada, que tomou a análise do currículo vivido do curso de formação de professores, aponta o movimento curricular de formação e profissionalidade docente do aluno/professor. Os resultados analisados com a realização desta investigação ajudam-nos a compreender que o currículo vivido no curso de pedagogia, por meio dos componentes curriculares, vem estabelecendo diálogos com o campo de atuação dos alunos-professores.

Portanto, nos discursos dos sujeitos é enfatizado que a relevância dos componentes se caracteriza por serem de natureza teórica e prática que possibilita o embasamento teórico para atuação na sala de aula. Também é enfatizado que os componentes são significativos quando possibilitam ao estudante relacionar o estudo teórico com o cotidiano da escola, da mesma forma que o componente contribui na medida em que promove a reflexão da própria prática.

Assim, podemos concluir que os sujeitos apontaram como maior contribuição os componentes que possibilitam um respaldo teórico para direcionar a prática do professor. Dessa forma, identificamos que os discursos indicam que o currículo vivido na instituição possibilita a aproximação das discussões teóricas com as demandas e urgências do campo de atuação, estabelecendo dessa maneira o diálogo entre a prática e a teoria.

\section{Referências}

ALMEIDA, Lucinalva Andrade Ataíde; LEITE, Carlinda; SANTIAGO, Maria Eliete. Um olhar sobre as políticas curriculares para formação de professores no Brasil e em Portugal na transição do século XX para o XXI. Revista Lusófona de Educação, Porto - Portugal, v. 23, n. 23, pp. 119-135, março/junho. 2013.

BALL, Stephen. Sociologia das políticas educacionais e pesquisa crítico-social: uma revisão pessoal das políticas educacionais e da pesquisa em política educacional. Currículo sem Fronteiras, Porto Alegre, v.6, n.2, pp.10-32, Jul/Dez, 2006.

BOURDONCLE, Raymond. La professionnalisation des enseignants: analyses sociologiques anglaises ey américaines. Revue Française de Pedagogie. Paris, n. 94, janvier-février-mars, pp. 73- 92. 1991.

BUSNARDO, Flávia; LOPES, Alice Casimiro. Os discursos da comunidade disciplinar de ensino de biologia: circulação em múltiplos contextos. Ciência \& Educação, Bauru, v. 16, n. 1, pp. 87-102, 2010.

CARMO, Priscilla Maria Silva do. Pesquisa e prática pedagógica: discursos sobre a profissionalidade das estudantes/professoras em formação. (151 f.) Dissertação (Mestrado em Educação) [? Programa de Pós-Graduação em Educação Contemporânea, Universidade 
Federal de Pernambuco ? Campus Acadêmico do Agreste, 2013.

CORREIA, José Alberto; FELGUEIRA, M. A análise de necessidades na formação profissional de professores: da identificação das carências ao sentido das experiências. Cadernos Pedagógicos. Formação de Professores: da racionalidade instrumental à ação comunicacional. Porto, Porto Editora, dezembro/1999.

CNPq, PROPESQ/UFPE. Políticas curriculares para a formação de professores: Uma análise do currículo vivido pelas les no curso de Pedagogia. Relatório Técnico Final, 108 págs., Caruaru, 2012.

FERREIRA, Suely. Reformas na Educação Superior: de FHC a Dilma Rousseff (1995-2011).

Linhas Críticas, Brasília, DF, n.36, pp. 455-472, maio/ago. 2012.

FRANÇA, Wilma Priscila Alves; ALMEIDA, Lucinalva Andrade Ataíde. As políticas curriculares e as novas demandas na formação do pedagogo: a atuação docente nos espaços não escolares. LUMEN, Recife, v.22, n.2, pp.43-52, jul/dez. 2013.

MAINARDES, Jefferson. Abordagem do ciclo de políticas: uma contribuição para a análise das políticas educacionais. Educ. Soc., Campinas, CEDES, vol. 27, n. 94, pp. 47-69, jan./abr. 2006.

MELO, Maria Júlia Carvalho de. Os sentidos partilhados sobre estágio supervisionado e as contribuições para a prática docente do professor com experiência docente. (188 f.). Dissertação (Mestrado em Educação) - Programa de Pós-Graduação em Educação Contemporânea, Universidade Federal de Pernambuco - Campus Acadêmico do Agreste, 2014.

MELO, Maria Julia Carvalho de; ALMEIDA Lucinalva Ataíde Andrade de. Estágio supervisionado e prática docente: Sentidos das produções discursivas da ANPEd, BDTD e EPENN. Revista Eletrônica de Educação, São Carlos - São Paulo, v. 8, n. 3, pp. 34-51, jun./ dez. 2014.

MELO, Maria Julia Carvalho de; SILVA, Maria Angélica da; ALMEIDA, Lucinalva Andrade Ataíde de. A construção histórica de sentidos sobre estágio supervisionado e didática nos cursos de pedagogia: uma análise a partir das produções teóricas. Revista Ibero-americana de Estudos em Educação, Espanha, v. 9, n. 1, pp. 60-70, jan./mar. 2014.

MINAYO, Maria Cecília de Souza (Org). Pesquisa social: teoria método e criatividade. 27. ed. Petrópolis, RJ: Vozes, 2008.

MORIN, E. A cabeça bem-feita: repensar a reforma, reformar o pensamento. Rio de Janeiro: Bertrand Brasil, 2000.

OLIVEIRA, Maria Marly de. Como fazer pesquisa qualitativa. Petrópolis, RJ: Vozes, 2007. OLIVEIRA, Inês Barbosa de. Contribuições de Boaventura de Sousa Santos para a reflexão curricular: princípios emancipatórios e currículos pensadospraticados. Revista e-curriculum, São Paulo, v.8, n.2, pp. 1-22, agosto 2012.

ORLANDI, Eni Puccinelli. Análise de discurso: princípios e procedimento. 9. ed. Campinas, SP: Pontes Editores, 2010. 
As formas do silêncio. Campinas: Ed. Unicamp, 1997.

SANTIAGO, Maria Eliete. Escola pública de 1o grau: da compreensão à intervenção. Rio de Janeiro: Paz e Terra, 1990.

. Projeto pedagógico da escola: uma contribuição ao planejamento escolar. $R$. Adm. Educ., Recife, UFPE, v. 1, n. 1, pp. 69-73, jul./dez., 1997.

SOUZA, João Francisco de. Prática pedagógica e formação de professores. Ensaio para concorrer ao cargo de professor titular. UFPE, Recife, 2006.

SOUZA JÚNIOR, Marcílio Barbosa Mendonça de. A constituição dos saberes escolares na educação básica. 2007. 345 f. Tese (Doutorado em Educação) - Centro de Educação, Universidade Federal de Pernambuco, Recife, PE, 2007.

TARDIF, Maurice. Os professores enquanto sujeitos do conhecimento: subjetividade, prática e saberes no magistério. In: CANDAU, V. (org.). Didática, currículo e saberes escolares. Rio de Janeiro: DP\&A, 2000.

. Saberes docentes e formação profissional. 9. ed. Petrópolis, RJ: Vozes, 2008.

VASCONCELLOS, Celso dos Santos. Planejamento: plano de ensino-aprendizagem e projeto educativo - elementos metodológicos para elaboração e realização. São Paulo: Libertad, 1995.

ZEICHNER, Kenneth M. A formação reflexiva de professores: ideias e práticas. Lisboa: Editora Educa, 1993.

Recebido em julho de 2014

Aprovado dezembro de 2014

Lucinalva Andrade Ataíde de Almeida é doutora em Educação pela Universidade Federal de Pernambuco (UFPE), com doutorado-sanduíche na Universidade do Porto e professora do Programa de Pós-Graduação de Educação Contemporânea da UFPE - Centro Acadêmico do Agreste (CAA). E-mail: nina.ataidedgmail.com

Janssen Felipe da Silva é doutor em Educação pela Universidade Federal de Pernambuco (UFPE) e professor do Programa de Pós-Graduação de Educação Contemporânea da UFPE - Centro Acadêmico do Agreste (CAA). E-mail: janssenfelipedahotmail.com

Carla Patrícia Acioli Lins é doutora em Sociologia pela Universidade Federal de Pernambuco (UFPE) e professora do Núcleo de Formação Docente da UFPE, Centro Acadêmico do Agreste (CAA). E-mail: aciolilins.carladgmail.com 